\title{
Point-of-Care Ultrasound as a Tool for Family Medicine
}

\author{
Katbryn Rooney, BA, Rusb Medical College \\ Ann Fam Med 2019;17:iii. https://doi.org/10.1370/afm.2351.
}

The Annals of Family Medicine encourages readers to develop a learning community to improve health care and health through enhanced primary care. Participate by conducting a RADICAL journal club. RADICAL stands for Read, Ask, Discuss, Inquire, Collaborate, Act, and Learn. We encourage diverse participants to think critically about important issues affecting primary care and act on those discussions. ${ }^{1}$

\section{HOW IT WORKS}

In each issue, the Annals selects an article and provides discussion tips and questions. Take a RADICAL approach to these materials and post a summary of your conversation in our online discussion. (Open the article and click on "TRACK Discussion/Submit a comment.") Discussion questions and information are online at: http://www.AnnFamMed.org/site/AJC/.

\section{CURRENT SELECTION}

\section{Article for Discussion}

Andersen CA, Holden S, Vela J, Rathleff MS, Jensen MB. Point-of-care ultrasound in general practice: a systematic review. Ann Fam Med. 2019;17(1):61-69.

\section{Discussion Tips}

Point-of-care ultrasound (POCUS) is a low cost, accessible imaging modality. Despite its growing popularity, POCUS training in family medicine residencies is limited and it is used by less than $10 \%$ of practicing family physicians for nonobstetrical examinations. ${ }^{2,3}$ This systematic review provides an opportunity to review the published literature on the use of and training for POCUS among general practitioners.

\section{Discussion Questions}

- What is a systematic review? What is a metaanalysis? How are they related?
- What is the Cochrane Collaboration? What is PRISMA?

- What questions are asked by this review?

- Were appropriate studies included in the authors' search?

- How were studies included or excluded? Were included studies relevant to the authors' question?

-What are the main findings?

- Were any meta-analyses completed? If not, why?

- What are sensitivity and specificity?

-What is the well-established problem of screening in a population with low pretest probability? What are false positives and why is this a relevant concept?

- How does this review advance beyond previous research and clinical practice on this topic?

- How might this review change your practice? How might it influence graduate medical education?

- How feasible is point-of-care ultrasound for your practice?

- What clinical applications of POCUS are most/least relevant to your practice?

- What future research would be most valuable to pursue?

\section{References}

1. Stange KC, Miller WL, McLellan LA, et al. Annals Journal Club: It's time to get RADICAL. Ann Fam Med. 2006;4(3):196-197. http:// annfammed.org/cgi/content/full/4/3/196.

2. Hall JW, Holman H, Bornemann P, et al. Point of care ultra-sound in family medicine residency programs: a CERA study. Fam Med. 2015;47(9):706-711.

3. Clinical Procedures Performed by Physicians at their Practice (as of December 31, 2017) -About Us. http://www.aafp.org/about/ the-aafp/family-medicine-facts/table-12(rev).html. Accessed Dec 13, 2018. 